\title{
A New Teaching Method of "Introduction to Computer Science" Course Inspired by the Operation Mode of Restaurant
}

\author{
Xiaodan Chen \\ Collage of information science and engineering \\ Chengdu University \\ Chengdu, China \\ Hongping Yuan \\ Collage of information science and engineering \\ Chengdu University \\ Chengdu, China
}

\author{
Siming Li \\ Collage of information science and technology \\ Chengdu University of technology \\ Chengdu, China \\ Junyan Zhang \\ Collage of information science and engineering \\ Chengdu University \\ Chengdu, China
}

\begin{abstract}
Introduction to Computer Science" is the first compulsory course for undergraduates majoring in computer science. This course covers the core knowledge of computer science, and needs to give students the right concept and sufficient interest to lay the foundation for future computer learning. It's important to choose a good teach method. As a matter of fact, the elements of teaching are similar to the elements of restaurant operation. Not only that, the university professional training plan liked the restaurant menu. And the course teacher's duty is same as the restaurant staff. Therefore, the restaurant operations inspired a new teaching method of "introduction to computer science". That is to say, the course teacher should fully analyze the characteristics of teaching objects, help students to understand the professional field, impart professional learning method, and think everything just like the restaurant staff.
\end{abstract}

Keywords-Introduction to Computer Science; Restaurant operation; Training plan; Teaching objects; Learning methods

\section{INTRODUCTION}

"Introduction to Computer Science" is the first compulsory course in computer science, which is learned by the first grade students who have almost no professional basis. This course involves some core knowledge of computer science such as programming language, logic circuit, system structure, operation system, algorithm design, complexity analysis, computer network, and information security, multi-core and distributed computing systems, and so on. Course Lecturers need to have a wide range of knowledge accumulation in computer science. They also should organize course content reasonably. The proper teaching method can be chose to make students understand the basic concepts of computer science correctly and generate great interest in it. So the foundation of professional study will be laid. "The introduction of computer science" course is both comprehensive and important in the field of computer science, so it is difficult to teach [1].

Sponsors: The Project of Chengdu University on Graduate Student Education and Teaching Reform in 2017(cdjgy2017009) ; The Project of Chengdu University on Undergraduate Education and Teaching Reform in 2017 ( cdjgb2017048)
Teaching method can draw on the idea of restaurant operation, which is benefit to achieve the expected teaching effect.

\section{COURSE TEACHING AND RESTAURANT OPERATION}

On the surface, course teaching and restaurant operations are the different two things, the former pays attention to learn, meets the demand of the human spirit, the latter cares about eating and drinking, meets people's material needs. In fact, there are many similarities.

\section{A. The comparison between course teaching elements and restaurant operation elements}

Course teaching has three main factors: classroom teachers (administrative teachers, course teachers) and students. Restaurant operation also has three main factors: dining venue, restaurant operators (managers, chefs, and waiters) and diners.

The first factors are both site. In the traditional sense, there should be a classroom for teaching, and a restaurant should have a storefront. But now, teaching and repast can be anywhere, not limited to a fixed location, with the popularity and development of intelligent terminals, personal computers, Internet and mobile Internet. People can order meals or learning knowledge through the network.

The second key elements are both operators. Teaching management personnel are responsible for the formulation of the professional training plan, the organization and supervision of teaching activities, the benign operation of teaching. Restaurant manager establish restaurant orientation, set menu, formulate and implement the restaurant institution, guarantee normal operation of the restaurant. Course teachers and chefs are processors and suppliers of resources. Course teachers process information, and supply knowledge. Chefs process ingredients and provide the food. Teachers must have the proper teaching methods to attract students. Chef should have their own cooking characteristics to attract diners. Some teachers and some posts of teaching management personnel act as the role of attendants, service for students' study and life. 
The third key elements, diners and students are consumers. Diners consume dishes. Customers' satisfaction is an important index of restaurant operations. Students consume knowledge. Students' learning effect is the goal of teaching quality assessment.

\section{B. Professional training plan is similar to restaurant menus}

When diners come to an unfamiliar restaurant, they may be attracted by the restaurant type, decoration style, cleanliness, etc. This has a lot of randomness. Students choose university major because of various factors, but have less knowledge about the specific learning content of the major.

For eating well at restaurant, it is very important to order the meal. It's similar to study. We should know what to learn. Because there is a lot of theory or technology to be learned, it just likes abundant dishes served by the restaurant. To order the meal, we firstly see the menu. The menu usually display items, such as cold dishes, fired dishes, steamed dishes, stews, soups, snacks and so on. Different restaurants have different classification method based on itself characteristics. Diners order a proper meal from different food category according to the tastes. The professional training plan is like a menu, which is a holistic plan for teaching content and teaching activities. It sets up school level compulsory course, subject compulsory course, professional compulsory course and elective courses. Students choose courses from different categories until the teaching goal is reached.

How to develop a professional training plan? Please take a look at how to customize the restaurant menu. The first step is to determine meal types of the restaurant, such as Chinese food, western food, hot pot or snacks, etc. The meal type depends on the managers' operation principle and localization. And then according to the meal types and characteristics, managers determine the menu. Professional training plan should have talents training goal firstly, such as training students into practical talents, research talents or applied research talents, etc. The professional talent training target is determined by the school development goals and characteristics of running a school. For example, the localization of Chengdu University is to "build a high level applied comprehensive university with distinct characteristics of running schools". So the training goal of computer science and technology professional of this university is "to cultivate the high-quality practical talents who can serve the regional economic development of Chengdu with development technology of embedded technology and the team cooperation spirit by carrying out professional cooperation with Intel, embedding in the corresponding curriculum system." Then, according to the training goal, correlated curriculums were set in the training plan. For example, the courses relating to the embedded technology were set in the professional training plan of computer science and technology of Chengdu University. This process is like to determine menu of dishes. Finally, courses were distributed in the proper semester according to the study sequence of knowledge.

\section{The "introductory" course teacher is like a waiter in a restaurant}

Professional training plan maybe is perfect, but it is really significant when teachers and students can understand it. Just like a chef and a diner, menu should be understood by both sides. In fact, the training plan is not easy to understand for everyone who did not come into contact with professional knowledge, which is like a person to travel to the strange country, even in the absence of language obstacles, the menu of dishes is not easy to confirm taste. Fortunately, the restaurant's attendants are responsible for introducing the meal, they know all the flavors and features of the dishes, and can help diners to match dishes. Who will be responsible for introducing the professional training plan? Introductory course was offered in freshman year which is related with profession, tentatively named "introductory" course here. For example, "introduction to computer science" is an "introductory" course to the computer science and technology professional. The "introductory" course teachers are going to act as a restaurant waiter, help freshmen to understand the cultivation plan, the research content and direction in the field of computer, sequentially planning their own study direction.

\section{A NEW APPROACH TO THE TEACHING OF COMPUTER SCIENCE INTRODUCTION}

If the role of "Introduction to Computer Science" course teacher is like a restaurant attendant, then the new teaching ideas can be inspired by the waiters' working contents and methods.

\section{A. To analyze the characteristics of the teaching object, just \\ like to analyze the demand of the customer}

In order to help guests order, the waiter should be able to fully understand the needs of the guests and give appropriate suggestions, which ensures that the restaurant has returned customers and keep a good operation. To achieve such a goal, the restaurant attendants need to have a look and see the customer's needs. In the same way, course teachers of " The Introduction to Computer Science " should fully understand the characteristics of teaching objects [2]. The teaching object of "Introduction to Computer Science" course is university freshmen who are post-95s now.

The first characteristic of post-95s: self-consciousness is stronger. The post-95s go after self-fulfillment and emphasize the importance of "self-standards" and do not use other people's judgment as the criterion for success [3]. In teaching, teachers should respect students' independent thinking and pay attention to the way of guidance.

Characteristic 2: having competitive consciousness. In the growth process, post-95s already know the competition is intense, also have the awareness of achieving the target by effort. But the character of post-95s is duality and variability, they are easy to fall in self-thinking, even self-contradiction. Therefore objective achievement scale is not high. Teachers can make full use of students' competitive awareness, set up after-school tasks and evaluation sessions, and stimulate students' learning initiative.

Characteristic 3: practical. In the period of rapid emergence of new things, the empty meaningless knowledge cannot satisfy the ideal and passion of post-95s. Teachers should pay attention to link theory and application scenarios, or program implementation, to avoid empty theoretical explanation. 
Characteristic 4: post-1995s have preliminary information acquisition ability. With the rapid development of information technology and the popularization of smart devices, it is possible to obtain a large amount of information through the Internet by post-95s. But the ability of organizing information needs to be strengthened. The teacher would set up a task of writing paper to improve students' ability in collecting and collating information.

Characteristic 5: lack of learning goals, easy to indulge themself and be Internet addiction. In order to test better or go to college, the post-95s toke part in various remedial classes and interest classes from the age of 4 and 5. It is the most important characteristic of this kind of study which learning goal is clear studying with the teacher's whole-process help. When they became undergraduates, the old learning goal had been achieved. But a new learning goal wasn't formed. Ever their lives were very drab with only three life scenes (school, cram school and family). They were restrained by parents, teacher. When the post-95s admitted to the university, study environment was relatively loose without various constraints. They suddenly had a freedom life. It's easy to indulge in online games, social networking, etc. In college classes, every college teacher was experiencing a battle with students' cell phones. Teachers had to pay attention to the maintenance of classroom discipline, correct the relaxed learning state, and give correct guidance to the learning goals.

\section{B. To help students understand the professional field, just like to help diners to order food}

In order to help diners order food, the waiter of the restaurant should introduce the food ingredients, cooking method, taste and so on. According to the menu, they guided the diners to go with the dishes -- cold and hot, with meat and vegetable. As a teacher who was majoring in introductory courses, how to introduce different fields of computer science and arrange the teaching content reasonably?

As with recipes, it is possible to introduce different professional fields' knowledge according to the training plan. The training program lists compulsory courses and elective courses. The compulsory course is the theoretical basis of the subject, which helps to form the basic professional quality. The specialized elective course embodied the latest development direction of subject theory or technology, and provided support for students' individuality development. To the major of computer science and technology, for example, common professional compulsory courses included the data structure, database principle and application, principle of operating system, computer network, the program design, software engineering, etc. [4] At the same time, elective course were set up such as cloud computing technology, for following the development of IT new technology [5]. The content design of "Introduction to Computer Science" course is like ordering food, which should pay attention to the combination of meat and vegetables.

So eight teaching topics were designed, which were computer hardware, computer software, algorithm, programming, database, computer network technology, information security and IT new technology. The topic of computer hardware was related to the numerical system and its operation methods, data storage and presentation problems, and the composition of computer hardware. The topic of computer software involved the theory of operating system and common application software. The algorithm topic included the representation of the algorithm, the basic method of the algorithm design, and the evaluation of the algorithm and so on. Programming topics included the execution of the program, data structures, etc. The database topic mainly introduced relational model and structured query language. The topic of computer network involved network architecture, web design and access, Internet of things technology and so on. The information security feature involved common threats, measures of nuclear technology and so on. IT new technology topics covered big data, cloud computing, artificial intelligence and other IT areas research hotspot.

Different types of specialized courses play different roles in training programs, which can enrich students' subject knowledge and meet the students' personality development requirements. By dividing the computer knowledge into eight topics, the "Introduction to Computer Science" teachers are more likely to lead students to understand computer science and help students to clear their learning direction. Of course, good design of teaching content also needs to cooperate with appropriate teaching method, which can make the student more easily accept knowledge. Based on the analysis of post-95 learning characteristics, teachers of "Introduction to Computer Science" should have a humorous and concise teaching style. The teaching content is vivid and operable, avoiding the empty. It is better to set up interactive links in teaching to give students more opportunities to express their ideas. And then setting up course tasks can stimulate students' competitive awareness, encourage innovation, and cultivate team spirit. Learning motivation can be enhanced by introducing the future of knowledge or technology [6].

\section{To impart professional learning methods, just like To guide the process of eating}

Different countries have different dining etiquette and methods, and different subjects have different learning methods. A freshman faced to the field of computer science, which was like to repast in a strange country. Changing the way of learning was a shared challenge to course teachers of "introduction to computer science" and college freshmen. As is well known, the computer technology updates faster and strong practicality. Therefore, the core of learning methods was how to effectively acquire knowledge. And it's important to set up the proactive study goal, ready to lifelong learning, use network learning resources scientifically. Our country had built the network learning platform with a high professional level. For example, "love course" net was constructed to resources sharing platform about the higher education curriculum by the ministry of education and ministry of finance during the period of "twelfth five-year" with starting the implementation of the "higher school undergraduate teaching quality and teaching reform project". Both Netease cloud class and Netease open class was the network learning platforms builted by Netease Corporation. Netease cloud classes offered online practical skills such as "Web Design" and "Techniques of Software Test" in the field of computer applications. Netease open class provided public class from the world and domestic famous 
universities such as Harvard University and Tsinghua University. We can find the Harvard University public class "Introduction to Computer Science" and MIT course "Introduction to Computer Science and Programming". The learning effect of knowledge was improved through the combination of on-line study and class.

\section{SUMMARY}

The effective implementation of curriculum teaching requires teachers to proper organize teaching content and to proper use of teaching methods, as well as students master learning methods. In order to achieve this goal, teachers should have an accurate understanding of the curriculum nature and status in the professional training plan, and have an accurate role. Course teachers of "Introduction to Computer Science" liken to waiters of the restaurant. After analyzing working content and methods of the restaurant staff, it was straightforward interpretation of "Introduction to Computer Science" course teaching content and method.

\section{REFERENCES}

[1] Su Chun, "The construction goal and thought analysis of Introduction courses to engineering", Journal of Southeast University (Philosophy and Social Science) Jun. 2015 Vol. 17,pp.151-154. (In Chinese)

[2] "Study report of the post-2000 population released by Ogilvy". China chain store, 2016,vol.4, pp.82-84. (In Chinese)

[3] Hu Wei. "Post-95 characteristics analysis based on education perspective”. Asia-Pacific Education,2016,vol.3, pp.290. (In Chinese)

[4] Liu Shuangqing ,Xia Liang. "Analysis and countermeasures of the problem in teaching of 'introduction to computers' from the military academic general education”. Computer engineering \& science,2014,vol.36,pp.267-269. (In Chinese)

[5] Sha Xingmian. Introduction to computer science by Python boat( the second edition). Beijing: Tsinghua University Press, 2016. (In Chinese)

[6] Cong Dianwei, Yang Li, Ma Biao. "Curriculum and thinking of teaching practice in freshman seminar cognitive navigation”. Science of Surveying and Mapping,2015,vol.40,pp.146-149. (In Chinese) 